\title{
OCCIPITALISATION OF ATLAS VERTEBRA AND ITS CLINICAL FRAMES OF REFERENCE- AN ANALYSIS
}

\author{
Dr. Neelima. $\mathrm{P}^{1 \rrbracket}$, Dr. Ravi Sunder. $\mathrm{R}^{2}$ \\ ${ }^{1}$ Professor and HOD, Anatomy, NRIIMS, Visakhapatnam-531162, Andhra Pradesh, India \\ ${ }^{2}$ Professor and HOD, Physiology, GIMSR, GITAM deemed to be University, Visakhapatnam-530045, Andhra Pradesh, India
}

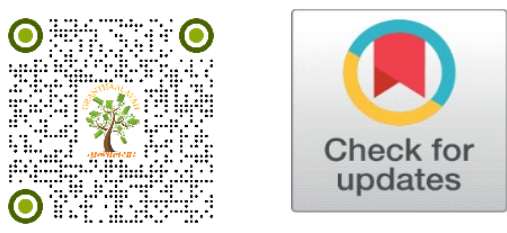

Received 01 September 2021

Published 30 September 2021

\section{CorrespondingAuthor}

Dr. Neelima. P,

drragamneelima@gmail.com

DOI 10.29121/jahim.v1.i1.2021.15

Funding: This research received no specific grant from any funding agency in the public, commercial, or not-for-profit sectors.

Copyright: (C) 2022 The Author(s). This work is licensed under a Creative Commons Attribution 4.0 International License.

With the license CC-BY, authors retain the copyright, allowing anyone to download, reuse, re-print, modify, distribute, and/or copy their contribution. The work must be properly attributed to its author.

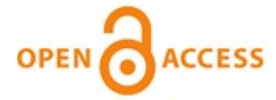

Accepted 15 September 2021

\section{ABSTRACT}

Vertebral column is made of 33 vertebrae named as cervical, thoracic, lumbar, sacral, and coccygeal vertebrae. Axial skeleton comprises of skull and vertebral column. 12 pairs of cranial nerves and 31 pairs of spinal nerves exit from the central nervous system which control the entire body. Malformations or fusion of vertebrae could be one of the etiologies of nerve compression syndromes. Vital structures emerge out through intervertebral foramina extending from cervical to coccygeal vertebrae. Occipitalisation of atlas, the first cervical vertebra is one of the emergencies leading to wide spectrum of presentations like chronic neck pain or foramen magnum syndrome or unconscious state due to compression of medulla oblongata. During routine examination of skull bones while teaching, one skull was found to exhibit assimilation of atlas. Photographs were captured and compared with normal skull. Thorough examination revealed incomplete occipitalisation of atlas. The anterior arch was completely fused but the posterior arch was bifid showing a split. The styloid process on right side seemed to be long and very close leading to compression of structures of styloid apparatus in addition. On observation, it was found to be a male skull. Fusion of vertebrae may be a congenital anomaly due to maldevelopment of somite's in forming vertebrae. Skeletal element of caudal 4th occipital somite forms the occipital bone and when it is fused with the proximal 1st cervical somite leads to occipitalisation of atlas. Acquired conditions like atlantoaxial subluxation, chiari malformations or cervical vertebral fusion or foramen magnum abnormalities have been associated with assimilation of atlas. The present study reports occipitalisation of atlas which is incomplete with a bifid posterior arch. Prevalence of such anomalies may form the differential diagnosis of chronic headache or myelopathies.

Keywords: Occipitalisation, Atlas, Myelopathy, Styloid Process, Dried Skull

\section{INTRODUCTION}

Vertebral column is a part of axial skeleton with 33 vertebrae forming the vertebral canal to protect spinal cord. Medulla oblongata, which is a part of rhombencephalon or hind brain, leaves the cranial cavity through foramen magnum and continues as spinal cord at the level of outer border of atlas, the first cervical vertebra. Assimilation of atlas in forming the cranial base is termed as

\footnotetext{
How to cite this article (APA): Neelima, P., and Sunder, R. R. (2021). Occipitalisation Of Atlas Vertebra and Its Clinical Frames of

Reference- An Analysis. Journal of Ayurvedic Herbal and Integrative Medicine, 1(1), 54-57. doi: 10.29121/j-ahim.v1.i1.2021.15 
occipitalisation. This is the most common malformation at the cranio vertebral junction. This can be radiologically diagnosed by lateral teleradiography as discussed by Kahouadji et al. (2013). Neurosurgeons or radiologists should be conscious about this variant anatomy at the cranio vertebral junction while diagnosing myelopathies or nerve compression syndromes. Khamanarong et al. (2013) evaluated the neurovascular symptoms of this congenital malformation. Surekha Jadhav et al. (2012) demonstrated the assimilation of atlas in Maharastra region. As stated by Srisopark (1974), the incidence was found to be 0.08-3\%. Though studies on occipitalisation of atlas insist on the clinical symptomatic presentations of neurological sequelae, a study by Gholve et al. (2007) explains the asymptomatic scenario observed in children. Wackenhein (1974) states that assimilation of atlas is variable in its tposition as it may involve any aspect of atlanto occipital articulation. In the present study, a skull with almost complete occipitalisation of atlas except at posterior arch was analysed and clinically correlated.

\section{MATERIALS AND METHODS}

On routine examination of dried skulls at the occipital region, one skull was found to show incomplete assimilation of atlas. Photographs were taken and compared with normal skull.

\section{RESULTS}

One dried skull exhibited incomplete occipitalisation of atlas. The anterior arch of atlas was completely fused. Posterior arch was found to be splitted with a gap in the center. The styloid process was long, and its tip was found close to the fused atlas. This is represented in the following pictures.

\section{Figure 1}

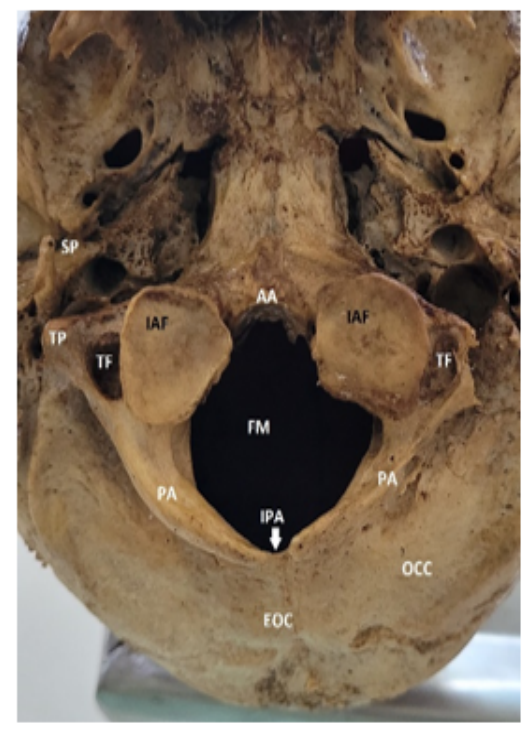

SP-styloid process; AA- anterior arch of atlas; TP- transverse process; TF- transverse foramen; IAF- inferior articular facet; FMforamen magnum; PA- posterior arch; IPA- incomplete posterior arch; EOC- external occipital crest; OCC- occipital bone

Figure 1 Norma Basalis Showing Occipitalisation of Atlas 
Figure 2
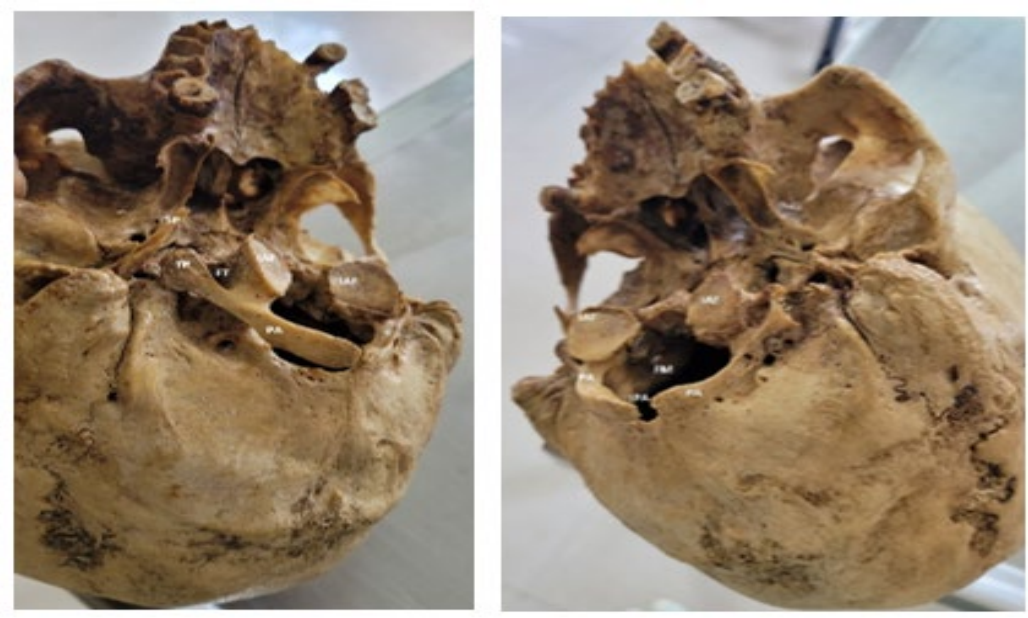

Figure 2 Lateral Views of Skull

Figure 3

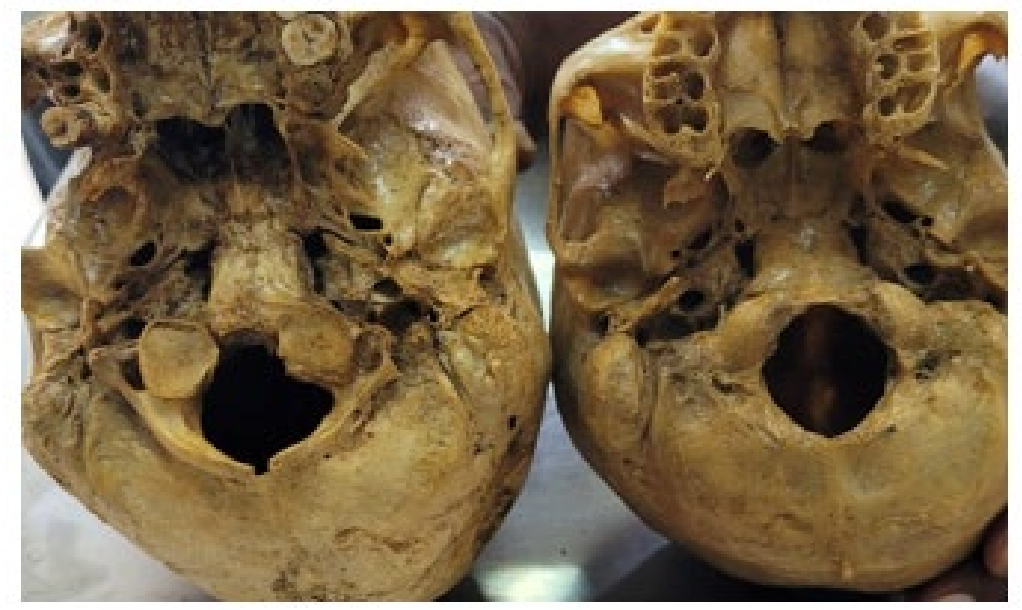

Figure 3 Comparison with Normal Skull

\section{DISCUSSION}

Assimilation of atlas is due to the fusion of caudal fourth occipital somite with proximal first cervical somite. Somite is a paraxial mesoderm derivative which is developed during 4th week of intrauterine life. 44 pairs of somites are formed on either side of the developing neural tube extending from cranial to caudal areas of the embryo. Each somite forms sclerotome, myotome, and dermatome where the entire vertebral column is derived from the sclerotome component. 4 occipital somite's form the skull base called the occiput. Normally, occipital somites and cervical somites' remain separate. Occipitalisation of atlas occurs when the last occipital somite fuses with the first cervical somite. Sween et al. (2014) demonstrated three skulls with occipitalisation of atlas. Nayak et al. (2005) put forth complete assimilation of atlas in their study. The main concern of such type of variant anatomy at the cranio vertebral junction is the wide spectrum of presenting symptoms. Howard and Simpson (1994) elaborated on the symptoms of paraesthesia's, numbness, impairment of 2-point discrimination, loss of vibration 
sense etc due to compression of dorsal columns. Kassim et al. (2010) analysed the myelopathies due to the compression. The wide range of neuro vascular complications due to such an anatomical variation should be borne in the minds of neurosurgeons or radiologists while dealing with such presentations. This study analyses the occipitalisation of atlas and its clinical frames of reference.

\section{CONCLUSION}

Incomplete occipitalisation of atlas with bifid posterior arch has been reported. This may lead to myelopathies or compression syndromes as vital structures like lower medulla becoming spinal cord, vertebral artery, cervical spinal nerves are related.

\section{CONFLICT OF INTERESTS}

None.

\section{ACKNOWLEDGMENTS}

None.

\section{REFERENCES}

Gholve, P. A. Hosalkar, H.S. Ricchetti, E.T. Pollock, A.N. Dormans, J.P. Drummond, D.S. (2007). Occipitalization of Atlas In Children. Morphologic Classification, Associationsand Clinical Relevance. J. Bone Joint SurgAm, 89, 571-578.

Howard, S. Simpson, J. (1994). Surgery of The Cervical Spine. London : CRC press, London.

Jadhav, S. Ambali, M. Patil, R. Doshi, M. Roy, P. (2012). Assimillation of Tlas In Indian Dry Skulls. JKIMSU, 1, 102-106.

Kahouadji E, Lucas O, Khonsari RH, Longis J, Hamel O, Corre P. (2013). Occipitalisation de l'atlas. Diagnostic Radiologique Et Implication Clinique

[Occipitalization of the Atlas. Radiological Diagnosis And Clinical Significance]. Rev Stomatol Chir Maxillofac Chir Orale.114(3),187-91.

Khamanarong, k. et al. (2013). Occipitalization of the Atlas : Its Incidence And Clinical Implications. Acta Medica Academica, 42(1),41-45.

Kassim, N.M. Latiff, A.A. Das, S.Ghafar, N. A. Suhaimi, F.H. Othman, F. et al. (2010). Atlanto-Occipital Fusion: An Osteological Study With Clinical Implications. Bratisl Lekárske Listy, 111(10), 562-5.

Nayak, S. Vollala, V.R. Raghunathan, D. (2005). Total fusion of Atlas With Occipital Bone : A Case Report. Neuroanatomy. (2), 39-40.

Srisopark, S. (1974). Occipitalization of the Atlas. JDentistry Association Thailand, 245(5), 294-299.

Sween, W. Modi, B. S. Puri, N. Patnaik, V. V. G. (2014). Occipitalization of Atlas. Int J Anat Res, 2(4) :781-784.

Wackenhein, A. (1974). Roentgen Diagnosis of The Craniovertebral Region. Newyork ; Springer-Verlag, 360-362. 